\title{
KNOWLEDGE, ATTITUDES, AND PRACTICES TOWARD CORONAVIRUS DISEASE-19 INFECTION AMONG RESIDENTS OF DELHI NCR, INDIA: A CROSS-SECTIONAL SURVEY BASED STUDY
}

\author{
UBADA AQEEL ${ }^{1}$, MOHAMMAD DAUD ALI ${ }^{2}$, ZEENAT IQBAL ${ }^{3}$, MOHD. AAMIR MIRZA ${ }^{3 *}$ \\ ${ }^{1}$ Department of Healthcare and Pharmaceutical Management, School of Management and Business studies, Jamia Hamdard, New \\ Delhi, India. ${ }^{2}$ Department of Pharmacy, Mohammed Al-Mana College for Medical Sciences, Dammam, Saudi Arabia. ${ }^{3}$ Department of \\ Pharmaceutics, School of Pharmaceutical Education and Research, Jamia Hamdard, New Delhi, India. Email: aamir_pharma@yahoo.com \\ Received: 05 July 2020, Revised and Accepted: 08 August 2020
}

ABSTRACT

Objective: In the given study, we have carried out a survey among general population of Delhi NCR (India) for the knowledge, perceptions, and attitude toward coronavirus disease (COVID-19) and also attempted to reach to a few conclusions in the form of recommendations.

Methods: A cross-sectional questionnaire based online survey (using Google Forms) was conducted between April 2020 and May 2020 to investigative knowledge, perceptions, and attitude toward COVID-19. Chi-square test was used for the computation of p-value.

Results: There were total 823 respondents, with $43.01 \%$ females and $56.98 \%$ males. Around $73.74 \%$ respondents believe that it has become a social stigma. About $75.09 \%$ were of the opinion that sneezing etiquettes can help in curbing the infection. About $93.43 \%$ of study population follows the personal hygiene, $24.78 \%$ wished to get insurance coverage. Similarly, interesting data were collected over different aspects of COVID-19.

Conclusions: The current pandemic is the first exposure at such a large scale to the existing population but with the progression of time, authorities and general population are collating knowledge about the same. It is to be fought at all the fronts such as medical, social, economic, and psychological. Hence, this type of survey becomes an important tool in decision making.

Keywords: Social stigma, Social media, Pandemic, AYUSH, Economy, Health insurance.

(C) 2020 The Authors. Published by Innovare Academic Sciences Pvt Ltd. This is an open access article under the CC BY license (http://creativecommons. org/licenses/by/4. 0/) DOI: http://dx.doi.org/10.22159/ajpcr.2020.v13i10.38943

\section{INTRODUCTION}

The coronavirus disease (COVID-19) disease which stemmed from a strain of zoonotic coronaviruses in China's Wuhan, was declared as a Public Health Emergency of International Concern and then as a global Pandemic by the World Health Organization on March 12, 2020 [1]. The World Health Organization has officially named it as the COVID-19 disease [2] and according to the nomenclature assigned by the International Committee on Taxonomy of Viruses, the virus is known as Severe Acute Response Syndrome (SARS-CoV-2) [3]. An outbreak similar to the current one with a lesser pathogenicity also occurred in 2003 and was named SARS-CoV [4]. A similar group of viruses was also held responsible for the Middle East Respiratory Syndrome Coronavirus-MERS-CoV in 2015 [5]. Despite having a considerably low fatality ratio than the SARS outbreak of 2003, the widespread and rapid transmissions of COVID-19 possess a significant threat to the population risking a large number of fatalities [6]. The ongoing pandemic has seen a rampant spread, and by August 4, 2020, it has reached 213 countries with $18,476,330$ confirmed cases and 698,224 deaths [7]. The first case of COVID-19 in India was reported in a patient on January 30, 2020 with a travel history to China. In the early stages, when the existence of the virus had not been identified, the patients showed pneumonialike symptoms. Although various experts have reported that the virus is undergoing continuous mutations and the characteristic symptoms have been seen varying in different populations, attributing to the immunity, strain of the virus, and the geography. Moreover, the asymptomatic cases remain as an unprecedented stressor for the healthcare systems worldwide.

The global economy is now en route to a severe, inevitable recession which will potentially trump the economic downfall observed during the Great Depression of 1929 and the stock market crash of 2008-2009, as speculated by experts. However, the depth and span of the economic impact depend on the success of the preventive measures employed to control the COVID-19 spread, the effectiveness of governmental policies and stimulus packages to alleviate liquidity problems in the small and mid-size enterprises and provide support to families under financial distress. A crucial determinant will be the way in which various businesses and companies react and prepare to re-start their operations. Moreover, above all, it depends on when and how the exit strategy for the current lockdowns would come into force [8].

Another risk factor that threatens the Indian population is the lack of consumer awareness toward the insurance industry. There is a huge gap in insurance coverage for most of the population and the insurance claims for COVID-19 that amounts only to INR 135 crores. The data submitted to the Union Finance and Health ministry indicate an approximate of $4 \%$ of total insurance coverage for the disease. There are variations in the extent of penetration of life insurance services compared to health [9]. Moreover, in a bid to offer an affordable and COVID-19-specific health insurance product, the Insurance Regulatory and Development Authority of India has introduced regulations for all general and health insurance companies to offer a standard COVID-19 policy, starting June 15, 2020 [10].

People have succumbed to symptomatic treatment/precautionary treatment either based on allopathic medicines used previously in other viral and similar infections or ailments, or with alternative systems of medicine such as Ayurveda, Unani, and Homeopathic. It is believed that knowledge and practices of Ayurveda and Yoga can be used in the prevention and as an adjuvant therapy to COVID-19 [7]. In these unprecedented circumstances, the role of paramedic professionals has undergone drastic changes but unfortunately these are underutilized [11]. Community pharmacy practice has emerged as one of the health professions that have a crucial role in responding to this public health crisis. During the current pandemic, it has been recognized that 
community pharmacies are often the first point of contact with the health system for individuals with COVID-19 related health concerns or the ones seeking reliable information and advice [11]. In the light of the current events, health-care digitalization is the need of the hour. Randomized trials (most of which were underpowered) have shown that clinical consultations conducted through a video link tend to be associated with high satisfaction among patients and staff; no difference in disease progression; no substantial difference in service use; and lower transaction costs compared with traditional clinic based care [12]. Similarly use of Robotics will not only minimize physical contact but will also reduce life threat to medical staff and doctors who are the front liners in the management of the COVID-19 pandemic [12]. Combining the functions of online discussions, e-consultation and realtime clinical data exchange, telemedicine can also provide technical support to the emerging need for workflow digitalization [13]. Notably, India has the second highest Internet Users in the world after China. It is advisable for people to keep themselves updated through reliable sources and especially with the information provided by the official institutions and government bodies [14]. Some strict restrictions have employed by the Government of India to facilitate pandemic preparedness and slow down the COVID-19 transmission, including the suspension of public transportation, the closing of public spaces, close management of communities, and isolation and care for infected people and contact tracing of the suspected cases.

To introduce and instil effective control measures and behavioral interventions, knowledge about basic hygiene practices and modes of disease transmission, and the advised measures in such an environment is, therefore, of vital importance. To achieve ultimate success against the ongoing encounter against COVID-19 in India, people's commitment to these control measures is necessary. According to the knowledge, attitude, and practices (KAP) theory, the KAP of the people concerning COVID-19 makes a huge impact on the preventive measures put into practice $[15,16]$. Insights gained from the SARS outbreak in 2003 suggest that the extent of knowledge and types of attitudes of the population towards infectious diseases are reflected in the spread of panic and fear among the general public, which can further complicate the attempts to prevent the spread of the disease $[17,18]$. Collating the data of a particular faction of the society and funneling into a conclusion becomes important. In the same context, survey studies have been carried out among health-care professional as well as general population to assess their perception and attitude toward COVID-19.

\section{METHODS}

\section{Study population}

A cross-sectional questionnaire based online survey was conducted between April 2020 and May 2020 among residents of Delhi-NCR (National Capital Region), India. A questionnaire was formulated to determine KAP toward COVID-19 infection. The questionnaire of survey was developed based on an ample search of the literature. Afterward, the first draft of the survey questionnaire was reviewed by four academic experts voluntarily who reviewed the survey questionnaire for any suggestions or amendments. Second draft of questionnaire were considered final version of the survey, used for the making online survey link on Google Forms ${ }^{\circledR}$. Before sending survey link to the residents of Delhi, NCR a pilot study were conducted for the validation of survey response. After validation of survey responses survey link of Google Forms ${ }^{\circledR}$ used for data collection.

\section{Sampling and data collection}

A systematic random sampling technique was carried out on 1050 people, with $\mathrm{k}=2$ and 900 convenient participants were chosen, but only 823 respondents agreed and returned the complete response to the questionnaire. Thus, the participation number was $91.44 \%$ $(823 / 900)$. The lead researcher shared Google Forms ${ }^{\circledR}$ link to all the convenient people in the community through social media and e-mail. After sharing the link for survey, they were remind also for the end date of survey. After closing of survey, the data were pulled from the survey link in the form of Excel Sheet for data analysis.

\section{Data analysis}

Descriptive statistics were used to analyze the data. The analysis of all statistical parameter including Wilsons 95\% CI was performed using SPSS statistical software for Windows version 26 (SPSS, IBM Inc., Chicago, USA). A Chi-square $\left(\chi^{2}\right)$ was used for calculation for $\mathrm{p}$-value and measured the association between and among variables that included the demographic characteristics, levels of knowledge, practice, and perception of respondents. The Wilsons 95\% CI was also used for calculation of respondent's responses. $\mathrm{p} \leq 0.05$ was considered as statistically significant.

\section{RESULTS}

An online survey, related to KAP during the pandemic was conducted in the Indian population. Table 1 gives the demographic details of the sample in terms of age, gender, education, marital status, and occupation. A total of 823 responses were obtained. All the participants were above 18 years of age and Indian origin. The study included only those participants who had a good understanding of English language and access to the internet. Hence, by default individuals with a higher level of education were included in the study. The widest possible range of education level was taken for the survey, that is, from the high school to the doctorate level, the highest qualification of participation was graduation and above (around 87\%). In the total respondents (i.e., 823), 353 (43.01\%) were females and 469 (56.98\%) were males. The survey was spread from 18 to $>60$ years of age, with around $75.94 \%$ respondents in the age group of 19-30. Table 2 includes the knowledge and attitude of general population toward COVID-19 infection. In response to the questions about the symptoms of COVID-19, 478 respondents $(50 \%$, $\mathrm{p}<0.001$ ) agreed that symptoms are similar to that of Pneumonia while $762(92.58 \%, \mathrm{p}<0.001)$ were updated that the fever, tiredness, dry cough, and difficulty in breathing are the main symptoms of the infection. Total 607 respondents $(73.74 \%, \mathrm{p}<0.001)$ have the opinion that COVID-19 has become a social stigma, that is why patients are reluctant to disclose their symptoms at the early stage. 742 participants $(90.15 \%, \mathrm{p}<0.001)$ were of the view that elderly

Table 1: Demographic characteristics of study participants

\begin{tabular}{|c|c|}
\hline Characteristics & Participants $(n=823), \%$ \\
\hline \multicolumn{2}{|l|}{ Gender } \\
\hline Male & $469,(56.98)$ \\
\hline Female & $354,(43.01)$ \\
\hline Age (mean $\pm S D)$ (years) & $38.2 \pm 1.95$ \\
\hline$\leq 18$ & $43(5.22)$ \\
\hline $19-30$ & $625(75.94)$ \\
\hline $31-45$ & $129(15.67)$ \\
\hline $46-59$ & $22(2.67)$ \\
\hline$>60$ & $4(0.48)$ \\
\hline \multicolumn{2}{|l|}{ Marital status } \\
\hline Unmarried & $622(75.57)$ \\
\hline Married & $200(24.30)$ \\
\hline Divorced & $1(0.12)$ \\
\hline \multicolumn{2}{|l|}{ Education level } \\
\hline Below high school & $4(0.48)$ \\
\hline High school & $14(1.70)$ \\
\hline Intermediate & $62(7.53)$ \\
\hline Diploma & $27(3.28)$ \\
\hline Graduate & $355(43.13)$ \\
\hline Post graduate & $309(37.54)$ \\
\hline Doctorate & $52(6.31)$ \\
\hline \multicolumn{2}{|l|}{ Occupation } \\
\hline Unemployed & $27(3.28)$ \\
\hline Student & $549(66.70)$ \\
\hline House wife & $34(6.56)$ \\
\hline $\begin{array}{l}\text { Employed (non-healthcare } \\
\text { professional) }\end{array}$ & $213(25.88)$ \\
\hline
\end{tabular}


Table 2: Knowledge and attitude of COVID-19 infection among community of Delhi, NCR population (823)

\begin{tabular}{|c|c|c|c|c|}
\hline Statements & Yes (\%) & No (\%) & Can't Say (\%) & p-value* \\
\hline Symptoms of COVID-19 are similar to Pneumonia. Is the statement correct? & $478(50.08)$ & $135(16.40)$ & $210(25.51)$ & $<0.05$ \\
\hline $\begin{array}{l}\text { Fever, tiredness, dry cough, difficulty in breathing are main symptom of COVID-19 } \\
\text { related infection }\end{array}$ & 762 (92.58) & $32(3.88)$ & $29(3.52)$ & $<0.05$ \\
\hline $\begin{array}{l}\text { Do you think elderly people (above age of } 60 \text { ) suffering from other chronic diseases are } \\
\text { more prone to COVID - } 19 \text { infection? }\end{array}$ & 742 (90.15) & $33(4)$ & $48(5.83)$ & $<0.05$ \\
\hline $\begin{array}{l}\text { Young adults are considered to have sufficient immunity, so there is no need to take } \\
\text { much preventive measures in them to prevent the infection by the COVID-19. Agree? }\end{array}$ & 116 (14.09) & $653(79.34)$ & $54(6.56)$ & $<0.05$ \\
\hline COVID-19 is due to the ingestion of unprocessed food. Agree? & $110(13.36)$ & $522(63.42)$ & $191(11.05)$ & $<0.05$ \\
\hline Do you believe that sneezing etiquettes are helpful in reduction of COVID-19 infection? & $618(75.09)$ & 87 (10.57) & $118(14.33)$ & $<0.05$ \\
\hline $\begin{array}{l}\text { Do you know there is no specific treatment and vaccine for COVID-19, but early } \\
\text { symptomatic treatment can help patients to recover from the infection? }\end{array}$ & 715 (86.87) & $28(3.40)$ & $80(9.72)$ & $<0.05$ \\
\hline General mask is enough to prevent the infection by the COVID-19. Agree? & $297(36.08)$ & $444(53.94)$ & $82(9.96)$ & $<0.05$ \\
\hline $\begin{array}{l}\text { COVID-19 infection will be successfully controlled by strictly following lockdown and } \\
\text { staying at home. Agree? }\end{array}$ & $632(76.79)$ & 105 (12.75) & $86(10.44)$ & $<0.05$ \\
\hline $\begin{array}{l}\text { COVID-19 infection has become a social stigma; therefore, the patients are reluctant to } \\
\text { disclose their symptoms at the early stage. Agree? }\end{array}$ & 607 (73.74) & 87 (10.57) & 131 (15.91) & $<0.05$ \\
\hline Do you think that the COVID-19 outbreak can impact the global economy? & $799(97.08)$ & $7(0.85)$ & $17(2.065)$ & $<0.05$ \\
\hline $\begin{array}{l}\text { Lower middle income stratum is going to suffer the most in India due to COVID-19 } \\
\text { infection? }\end{array}$ & 743 (90.27) & 18 (2.187) & $62(7.53)$ & $<0.05$ \\
\hline
\end{tabular}

${ }^{*}$ p-value calculated using Chi-square $\left(\chi^{2}\right)$ test, $p \leq 0.05$ consider as statistically significant

people (age $>60$ years) suffering from other chronic diseases are prone to COVID-19 infection; moreover, 653 participants (79.34\%, $\mathrm{p}<0.001)$ disagreed to the question that there is no need to take much preventive measures among young adults who are considered relatively to be more immune. This shows that people are getting updated and concerned about the public health. Participants were equally aware of the precautionary measures to be taken and a trend has been observed. 632 respondents $(76.79 \%, \mathrm{p}<0.05)$ believed that strictly following lockdown can successfully control COVID-19 infection, while $618(75.09 \%, \mathrm{p}<0.05)$ participants believed that sneezing etiquettes can help in curbing the infection. Moreover, 444 respondents $(53.94 \%, \mathrm{p}<0.001)$ disagreed on the point that that just wearing general masks is enough to prevent the COVID-19 infection.

Economic impact of COVID-19 was the primary concern cited by the highest number of individuals, where 799 (97.08\%, p<0.05) participants actually thought that COVID-19 can impact global economy whereas $743(90.27 \%, \mathrm{p}<0.05)$ participants were of the view that lower and middle income stratum is going to suffer the most in India.

Table 3 describes the practices related to COVID-19 infection among general population. People preferred to live with less number of partners during the lockdown. 263 participants were living with $\leq 3$ partners while 342 participants with 4-5 partners as a measure to reduce the risk of infection. Awareness among the sampled population of hygiene appeared to be very high. A significantly high percentage of total respondents $(93.43 \%)$ cleaned their houses every day and did relate this habit to recommended hygiene practice. However, the degree of awareness gradually declined from personal hygiene practices to those which involve community/municipal services. Only 477 respondents $(57.95 \%)$ said that their locality is cleaned daily while 346 said it is cleaned weekly. Looking at the insurance coverage status, $203(24.66 \%)$ respondents already had it and approximately the same number of respondents (24.78\%) wished to get it post COVID-19. Surprisingly, 174 respondents (21.14\%) still do not want to get health insurance and 242 respondents $(29.40 \%)$ are not sure about it. The less encouraging response about the insurance coverage may be due to prevailing economic crisis and they wish to live with parsimony.

The majority of the respondents agreed that misinformation and rumors are spreading at a much faster pace than the current outbreak of COVID-19 (85.29\%). That is why the majority of participants believe that the reliable source of information forCOVID-19 is the scientists/ doctors $(60 \%)$ while $26.73 \%$ and $14.21 \%$ relied on government and

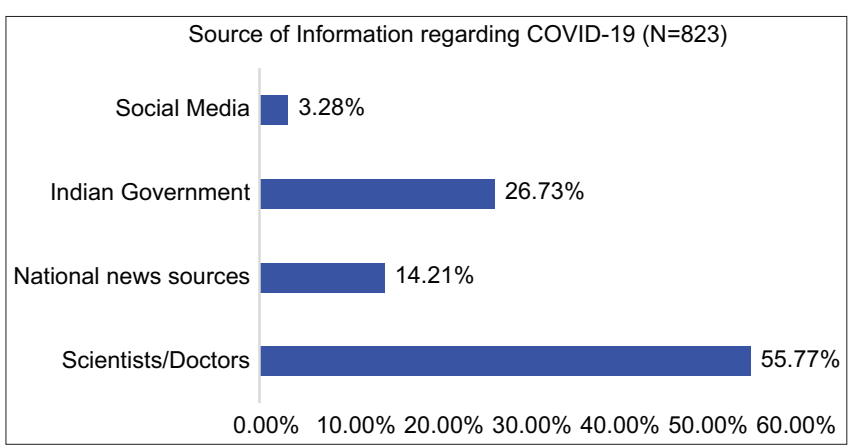

Fig. 1: Information sources reported by respondents

national news sources, respectively, as shown in Fig. 1. People expressed their adherence to stop the spread as 800 respondents (97.20\%) were found embracing to the stated five basic steps to stop the spread which includes: Washing hands frequently, coughing into the elbow, maintain physical distancing, use mask, and stay home as much as possible. It indicates that the government and other agencies have been successful in dissemination of the right information even to the last person in the queue.

Over the questions of treatment and consultation there was also a trend. 573 participants $(69.62 \%)$ shared that they would prefer Allopathic doctor to take suggestion/advice in case of any disease, followed by $19.07 \%$ participants for alternative systems of medicine (AYUSH). In case of unavailability of allopathic doctors, 318 respondents $(38.63 \%, \mathrm{p}<0.05)$ prefer practitioners of alternative system of medicine over pharmacist (32.19\%) and other health-care professionals (24.30\%). 313 (38.03\%, $\mathrm{p}<0.05$ ) respondents also showed interest in getting consultation from doctors over digital platform while $333(40.46 \%, \mathrm{p}<0.05)$ respondents said they still prefer getting consultation from doctors practicing in hospitals. When asked about their preferences, in case they experience symptoms like that of COVID-19 (fever/cough/breathlessness), 714 participants $(86.75 \%)$ preferred visiting government center/private hospital specified for COVID-19. Similarly, in case of any illness/ symptoms not associated with COVID-19, 502 (60.20\%) participants said they would visit government center/private hospital, followed by self-medication (30.25\% participants). Taking indigenous medicine/ herbal medicine, performing prayer and consultation with the religious priests are the last resort. On being asked if physical distancing/extraprecaution will make doctors less compassionate/approachable, we 
Table 3: Practice COVID-19 infection among community of Delhi, NCR population (823)

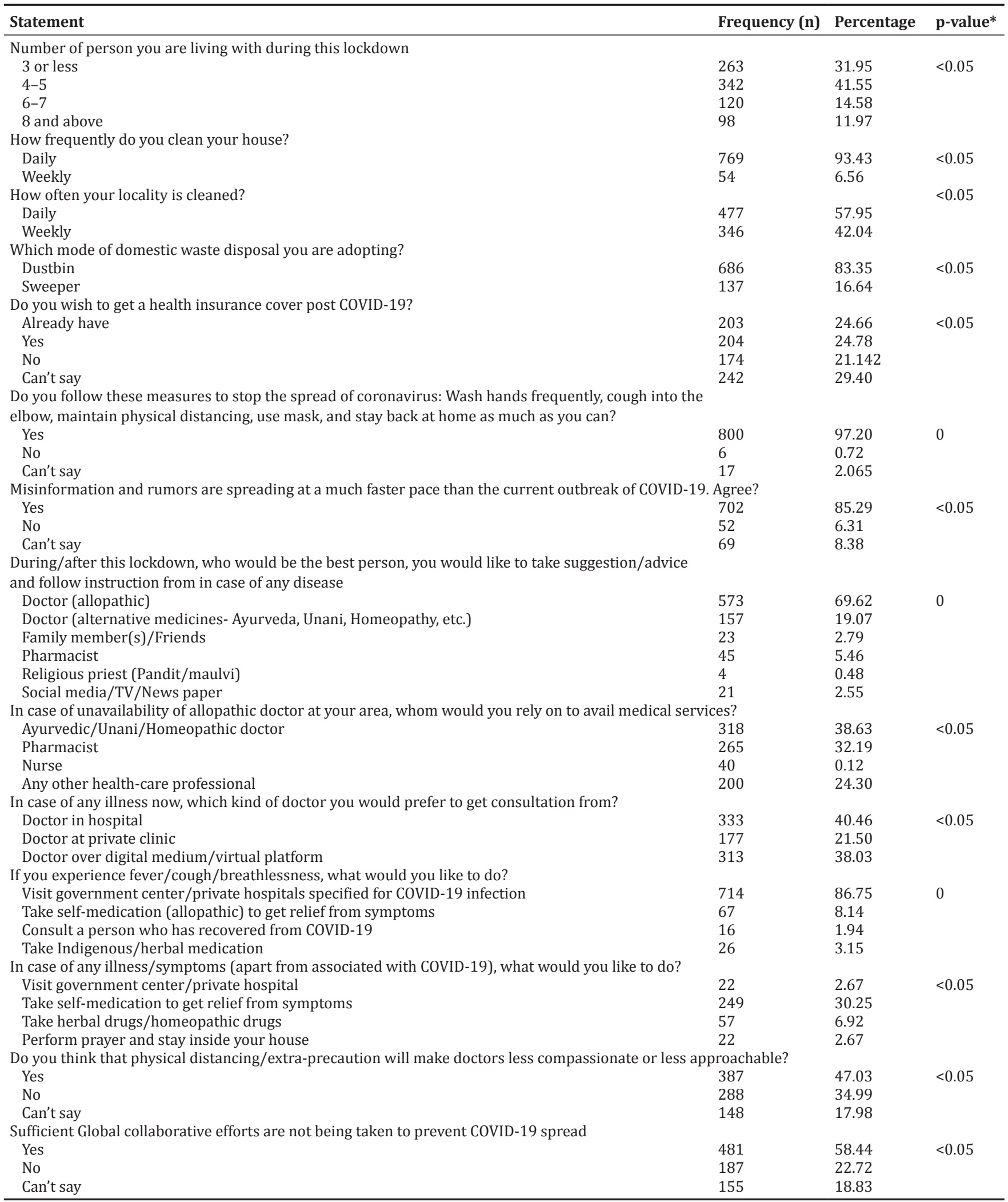

${ }^{*}$ p-value calculated by using Chi-square $\left(\chi^{2}\right)$ test, $p$-value $\leq 0.05$ consider as statistically significant

obtained a mixed response where 387 respondents $(47.03 \%, \mathrm{p}<0.001)$ answered in "yes" while 288 respondents (34.99\%, p<0.05) still believed that it will not affect the approachability. There is an amount of confusion among respondents over sufficient global collaborative efforts to be taken to prevent COVID-19 spread. 481 respondents (58.44\%, $\mathrm{p}<0.05$ ) thought that sufficient efforts are not being taken while 187 respondents (22.72, $\mathrm{p}<0.05)$ thought otherwise and 155 (18.83\%, $\mathrm{p}<0.001)$ could not say anything about it. 


\section{DISCUSSION}

In this predominantly male and well-educated sample, we found more than $60 \%$ correct answers on the questions related to knowledge, which indicates that most of the respondents were updated about COVID-19. This high score about knowledge among Indian residents was encouraging. This may be because there has been a widespread dissemination of information through various media channels as well as by the government at various levels $[19,20]$. Moreover, the participation of respondents like higher education stratum also supported our study and similar trends were observed in a study conducted in China [21]. However, these findings are in contrast to a study conducted in Iran on the same parameters of KAP [22]. Most of the respondents possess knowledge about the clinical symptoms, spread, and prevention of the disease when asked the myth buster questions. A little irrelevant question was also asked about the role of unprocessed foods for which there were some rumors in social media. About $63.24 \%$ participants knew that ingestion of unprocessed food will not spread the infection.

In our study, a strong relationship was seen between knowledge, positive attitude, and practices. About $76.79 \%$ population agreed that COVID-19 infection can be successfully controlled by strictly following lockdown and staying at home and only wearing general mask is not enough $(53.94 \%)$. This can be attributed to the strict measures taken globally regarding the lockdown and secondly due to good acceptance and actions followed by the people. About $97.20 \%$ participants followed good practices of: Washing hands frequently, coughing into the elbow, maintaining physical distance, and stay back at home as much as possible. Another study also corroborates our results [23]. Second, the unidirectional efforts from people across the country also increase confidence to overcome the pandemic. According to the Indian Council of Medical Research, there production factor $\left(\mathrm{R}_{0}\right)$ of SARS-CoV-2 was 2.5. In general, one sick person can infect 406 persons in 30 days, but if lockdown is strictly followed and social distancing is maintained, one sick person can infect just 2.5 persons [19]. Hence, we can say that the social distancing is the major way out for successful containment of pandemic, which has been shown in the pandemics of influenza [24]. The vast majority of the participants also held an optimistic attitude toward the COVID-19 pandemic. About $86.87 \%$ of the respondents believed that though there is no specific treatment and vaccine for COVID-19, early symptomatic treatment can help patients to recover from the infection. The observation is also supported by a study conducted in South France [25].

COVID-19 is a new disease which has shown continuous changes in its emergence, symptoms, and pattern of spread. There is an insufficient research regarding the novel coronavirus and the constant changes in the nature of the illness have become a cause of confusion, anxiety and fear among the common people. This has given rise to hatred and stigmatization of the patients who have been infected and also the healthcare workers. The people from north eastern part of the country are facing oppression and have become a target for the rumors of instigating the coronavirus spread in India. That is why it is very important to wipe out this stigma otherwise it will encourage people to hide their illness and discourage them not to seek healthcare immediately [26]. Results supporting this have also been found in our study where $73.74 \%$ respondents agreed that COVID-19 has become a social stigma and patients are reluctant to disclose their symptoms at the early stage. Not disclosing symptoms at early stage due to social stigma and efficacy of early symptomatic treatment in the prevention of this pandemic are negatively correlated. To address this problem providing online mental health consultation can be a solution [27].

The global coronavirus pandemic has widely disrupted the health and life insurance landscape. The health insurance market has seen a recent surge in consumer interest toward term life insurance plans as compared to others. Policy providers such as "Policybazaar" have seen a demand spurt of around $40 \%$ in health insurance policies, as compared to the policy demand data from last year. Insurers and policymakers are positive that the market will continue to follow similar trends of rising consumer interest and services demand even in the post-COVID era. [28]. In our study, just $24.78 \%$ respondents wished to get health insurance post COVID-19. It could be attributed to more number of unemployed and house wives as the respondents which lack decisionmaking.

In this unprecedented situation, there has been a natural havoc around the world and people started looking for correct and accurate sources of information about COVID-19 infection. About 55.77\% participants relied on scientist/doctors for this sort of information and it was surprising that just $3.28 \%$ people looked at social media for the information. Surprisingly, India had 351.4 million social media users till 2019 [29]. It can be seen either ways, that is, government is controlling the spread of misinformation or government channels have been successful in dissemination of the correct information. The majority of the respondents (85.29\%) agreed that misinformation and rumors spread at a much faster pace than the current outbreak of COVID-19. This spread of misinformation at a higher pace has been studied earlier also [30], which is in sync with our observation. Most popular social media platforms such as Facebook, Twitter, and YouTube provide a direct access to the unverified content and may increase many folds the spread of rumors and unreliable information [31]. The term "Infodemic" [32] has been coined to outline the perils of misinformation phenomena during the management of virus outbreaks [33]. It could even speed up the epidemic process by influencing and fragmenting social response. The spread of the pandemic is also associated with the spread of "fake news" and misinformation, especially through social media, which have led to a multitude of misconceptions regarding this novel disease. The government should take matters into its own hands and ensure that various traditional and new media platforms are effectively employed to provide timely and accurate information to the public, with data based on evidence and thorough research [34].

Indian Government, State health agencies, and several NGOs used various media platform to educate and increase awareness of the precaution and preventive measures to be taken [35]. Overall hygiene always plays a very important factor to prevent the spread of these kinds of infections. As high as $93.43 \%$ of the respondents were educated and doing well, when it comes to cleaning their houses daily to prevent the spread of the infection but it was disappointing to see that similar hygienic steps are not being taken on locality level. Although various cleanliness and disinfection drives have been carried out by the civic authorities to curb the spread, which was also seen when plague epidemic engulfed India in 1994.

In our study, less encouraging responses were obtained toward the acceptability of counseling with doctors over virtual/digital platforms. It was a surprise because India has the second highest users' base of Internet standing just after China [36]. India has also significant proportions of internet users both in urban and rural areas [37]. It was encouraging that $69.62 \%$ respondents still prefer allopathic doctors for consultation in case of any illness. Only in case of non-availability of allopathic doctors they like to either go to Ayurvedic/Unani/ Homeopathic practitioners (38.63\%) or to pharmacist (32.19\%) for consultation. Thus, the role of pharmaceutical care is significant for people with chronic illnesses and is particularly relevant during the COVID-19 pandemic period where many people have various medicinesrelated concerns. The option of consultation with pharmacists has been studied earlier also and corroborates our results [38]. In this unprecedented situation, the health-care system is already burdened and under tremendous stress. That is why reliability over alternative system of medicine as shown in our study is appreciable. It has been shown that Indian traditional medicinal systems plays an important role in encountering global health-care needs [38]. Faith in alternative system of medicine shown by around 39\% participants in this COVID-19 pandemic is also supported by a study [11] which suggests that Ayurveda and Yoga have the potential to address the challenges posed by this pandemic. 
The government should develop more and more centers/private hospitals dedicated for COVID-19 as $86.75 \%$ people suggested they would visit these centers in case of COVID-19 such as symptoms and otherwise as well. The country needs an additional 2.4 million nurses to meet the growing demand. Looking at the high demand of government/ private hospitals from our data, we would recommend that policy makers/government should devise some strategies to cope up with the increasing demand. Most of the respondents have discouraged the practice of self-medication which is good sign for our health-care system.

By this time, we all know that spread of COVID-19 has brought global economy to its knees. There could be two reasons for it. First, spread of this infection led to shut down of financial markets, corporate offices, and business. Second, the rate at which it is spreading and uncertainty is looming, its control led to decrease in consumption and investments. Even in our study, $97.08 \%$ participants thought that COVID-19 would impact global economy which is further substantiated by International Monetary Fund's remarks. According to IMF, the global economy is expected to shrink by over 3\% in 2020 - the steepest slowdown since the Great Depression of the 1930s [39]. World's topmost economies such as the US, China, UK, Germany, France, Japan, and many others are at the verge of collapse [40]. India also does not seem far-behind, $90.27 \%$ participants suggested that the lower and middle income groups will suffer the most in India due to COVID-19. The Economic Survey of 2018-2019, released on July 4, 2019, says "almost 93\%" of the total work-force is informal and according to periodic labor force survey $2017-2018,6.1 \%$ of India's Labor Force, and $17.8 \%$ of young people (15-29 years) in the labor force are unemployed. Results in our study are ratified by two studies. First, acute Ratings and Research estimate that Indian economy would lose over $\$ 4.5$ billion every day of the lockdown (https://www.acuite.in/acuite-in-news.htm, accessed on April 3, 2020). Second, Barclay's research estimates that the loss of output due to shuttered factories and closed offices works out to about $\$ 26$ billion per week and also estimates that India's 2020 GDP growth rate around zero.

The world is fighting against an unknown and invisible enemy. The enemy does not respect any border or hierarchy and unfortunately has exposed the fragilities in our system that is why we need a global compact to share responsibilities. Even in our study, 58.44\% respondents believed that sufficient global collaborative efforts are not being taken to prevent the COVID-19 spread.

\section{CONCLUSION}

During the initial days of the outbreak, there were not much knowledge and awareness of the different aspects of the infection but with the progression of time the general population is becoming aware and we have got significantly appreciable response about the symptoms of the disease, awareness, uncertainty about the drug/vaccine discovery and socio-economic angle of the pandemic. Several recommendations/ suggestions have also been drawn that may help in policy making. Although statistically acceptable, more studies are warranted to investigate the KAP toward COVID-19 among Indian residents.

\section{AUTHORS' CONTRIBUTIONS}

Mr. Ubada Aqeeland Dr. Mohd. Aamir Mirzacarried out the data collection. Dr. Mohammad Daud Ali carried out the data analyzing the results of the study, whereas Dr. Zeenat Iqbal reviewed the literature. Mr. Ubada Aqeeland Dr. Mohd. Aamir Mirza wrote the manuscript. All the authors read and approved the final version of the manuscript.

\section{CONFLICTS OF INTERESTS}

All the author(s) declared that they have no conflicts of interest none.

\section{AUTHORS' FUNDING}

None.

\section{REFERENCES}

1. Cucinotta D, Vanelli M. WHO declares COVID-19 a pandemic. Acta Biomed 2020;91:157-60

2. Huang C, Wang Y, Li X, Ren L, Zhao J, Hu Y, et al. Clinical features of patients infected with 2019 novel coronavirus in Wuhan, China. Lancet 2020;395:497-506.

3. Wu JT, Leung K, Bushman M, Kishore N, Niehus R, de Salazar PM, et al. Estimating clinical severity of COVID-19 from the transmission dynamics in Wuhan, China. Nat Med 2020;26:506-10.

4. Zhong N, Zheng B, Li Y, Poon L, Xie Z, Chan K, et al. Epidemiology and cause of severe acute respiratory syndrome (SARS) in Guangdong, people's republic of China, in February, 2003. Lancet 2003;362:1353-8.

5. Wang N, Shi X, Jiang L, Zhang S, Wang D, Tong P, et al. Structure of MERS-CoV spike receptor-binding domain complexed with human receptor DPP4. Cell Res 2013;23:986.

6. Crunching the Numbers for Coronavirus. Available from: https://www. imperial.ac.uk/news/196137/crunching-numbers-coronavirus. [Last accessed on 2020 Mar 20].

7. Coronavirus Cases. Available from: https://www.worldometers.info/ coronavirus. [Last accessed on 2020 Aug 04].

8. Fernandes N. Economic Effects of Coronavirus Outbreak (COVID-19) on the World Economy; 2020. Available from: https://www.ssrn.com/ abstract $=3557504$

9. Less Than $4 \%$ of Covid-19 Patients in India Have Insurance. Available from: https://www.economictimes.indiatimes.com/wealth/ personal-finance-news/less-than-4-of-covid-19-patients-in-indiahave-insurance/articleshow/76229514.cms?utm_source=whatsapp pwa\&utm medium $=$ social\&utm campaign $=$ socialsharebuttons \& from $=m \overline{d r} \&$ fbclid $=I w A R 1 Z \overline{I I} 1 Q$ SB 29JKdsfL 7jZFSCMD qkdMkbsBMGSoItP81SXMJhbzJDWb9aG0M. [Last accessed on 2020 Aug 04].

10. Will a Standard Covid-19 Health Insurance Benefit You? Available from: https://www.livemint.com/money/personal-finance/will-astandard-covid-19-health-insurance-benefit-you-11591257190036. html. [Last accessed on 2020 Aug 04].

11. Tillu G, Chaturvedi S, Chopra A, Patwardhan B. Public health approach of ayurveda and yoga for COVID-19 prophylaxis. J Alternat Complement Med 2020;26:360-4.

12. Whitfield S, MacQuarrie A, Boyle M. Trained, ready but underutilised: Using student paramedics during a pandemic. Aust J Paramed 2020;17:799.

13. Greenhalgh T, Wherton J, Shaw S, Morrison C. Video consultations for covid-19. BMJ 2020;368:m998.

14. Is the New Coronavirus Infodemic Spreading Faster than the Virus? Available from: https://www.euronews.com/2020/03/13/is-the-newcoronavirus-infodemic-spreading-faster-than-the-virus. [Last accessed on 2020 Aug 04].

15. Zhai Y, Wang Y, Zhang M, Gittell JH, Jiang S, Chen B, et al. From Isolation to Coordination: How can Telemedicine Help Combat the COVID-19 Outbreak? medRxiv; 2020

16. Ajilore K, Atakiti I, Onyenankeya K. College students' knowledge, attitudes and adherence to public service announcements on Ebola in Nigeria: Suggestions for improving future Ebola prevention education programmes. Health Educ J 2017;76:648-60.

17. Tachfouti N, Slama K, Berraho M, Nejjari C. The impact of knowledge and attitudes on adherence to tuberculosis treatment: A case-control study in a Moroccan region. Pan Afr Med J 2012;12:52.

18. Person B, Sy F, Holton K, Govert B, Liang A. Fear and stigma: the epidemic within the SARS outbreak. Emerg Infect Dis 2004;10:358.

19. Tao N. An analysis on reasons of SARS-induced psychological panic among students. J Anhui Inst Educ 2003;21:78-9.

20. Tomar BS, Singh P, Nathiya D, Suman S, Raj P, Tripathi S, Chauhan DS. Indian Communitys Knowledge, Attitude and Practice towards COVID-19. medRxiv; 2020.

21. Coronavirus N. Advice for the Public: Myth Busters. Availabe from: https://www.whoint/emergencies/diseases/novel-coronavirus-2019/ advice-for-public/myth-busters. [Last accessed on 2020 Mar 03].

22. Zhong BL, Luo W, Li HM, Zhang QQ, Liu XG, Li WT, et al. Knowledge, attitudes, and practices towards COVID-19 among Chinese residents during the rapid rise period of the COVID-19 outbreak: A quick online cross-sectional survey. Int J Biol Sci 2020;16:1745.

23. Erfani A, Shahriarirad R, Ranjbar K, Mirahmadizadeh A, Moghadami M. Knowledge, attitude and practice toward the novel coronavirus (COVID-19) outbreak: A population-based survey in Iran. Bull World Health Organ 2020;2020:256651

24. World Health Organization. WHO Checklist for Influenza Pandemic 
Preparedness Planning: World Health Organization; 2005. Avilable from: https://www.who.int/csr/resources/publications/influenza/ WHO_CDS_CSR_GIP_2005_4/en. [Last accessed on 2020 Mar 03].

25. Gautret P, Lagier JC, Parola P, Meddeb L, Mailhe M, Doudier B, et al. Hydroxychloroquine and azithromycin as a treatment of COVID-19: Results of an open-label non-randomized clinical trial. Int J Antimicrob Agents 2020;56:105949.

26. Roy D, Tripathy S, Kar SK, Sharma N, Verma SK, Kaushal V. Study of knowledge, attitude, anxiety and perceived mental healthcare need in Indian population during COVID-19 pandemic. Asian J Psychiatry 2020;51:102083

27. Yao H, Chen JH, Xu YF. Rethinking online mental health services in China during the COVID-19 epidemic. Asian J Psychiatry 2020;50:102015.

28. Covid-19: Health and Term Insurance Covers Gain Traction. Available from: https://www.livemint.com/money/personal-finance/covid-19health-and-term-insurance-covers-gain-traction-11590922374124. html. [Last accessed on 2020 Aug 04].

29. Number of Social Network Users in India from 2015 to 2019. Available from: https://www.statista.com/statistics/278407/number-of-socialnetwork-users-in-india. [Last accessed on 2020 Apr 20].

30. Vosoughi S, Roy D, Aral S. The spread of true and false news online. Science 2018;359:1146-51.

31. Cinelli M, Quattrociocchi W, Galeazzi A, Valensise CM, Brugnoli E, Schmidt A, et al. The COVID-19 social media infodemic. ArXiv; 2020.

32. Zarocostas J. How to fight an infodemic. Lancet 2020;395:676.
33. Mendoza M, Poblete B, Castillo C. Twitter under crisis: can we trust what we RT? In: Proceedings of the First Workshop on Social Media Analytics (SOMA'10). New York, USA: Association for Computing Machinery; 2010. p. 71-9.

34. Raza G, Dutt B, Singh S. Kaleidoscoping public understanding of science on hygiene, health and plague: A survey in the aftermath of a plague epidemic in India. Public Underst Sci 1997;6:247-68.

35. Mohammed MA, Moles RJ, Chen TF. Impact of pharmaceutical care interventions on health-related quality-of-life outcomes: A systematic review and meta-analysis. Ann Pharmacother 2016;50:862-81.

36. Number of Internet Users in India from 2015 to 2020 . Available from: https://www.statista.com/statistics/255146/number-of-internet-usersin-india. [Last accessed on 2020 Apr 20].

37. Number of Internet Users in India from 2017 to 2018 with a Forecast for 2019. Available from: https://www.statista.com/statistics/751060/ number-of-internet-users-by-region-india. [Last accessed on 2020 Apr 20].

38. Ravishankar B, Shukla V. Indian systems of medicine: A brief profile. Afr J Tradit Complement Alternat Med 2007;4:319-37.

39. Explained: How Covid-19 Has Affected the Global Economy. Available from: https://www.indianexpress.com/article/explained/explainedhow-has-covid-19-affected-the-global-economy-6410494. [Last accessed on 2020 Aug 04].

40. Impact of Covid-19 on Global Economy Structure. Available from: https://www.moderndiplomacy.eu/2020/04/22/impact-of-covid-19-onglobal-economy-structure. [Last accessed on 2020 Apr 30]. 